\title{
ADVANCING STATISTICAL EDUCATION USING TECHNOLOGY AND MOBILE DEVICES
}

\author{
Najeeb Al-Matar \\ AlBaha University, Saudi Arabia \\ nalmatar@bu.edu.sa
}

\begin{abstract}
This study explores individual differences and the effects of these differences on usage of a statistics website, especially in combination with new platforms, such as mobile devices (i.e. smart phones and iPods). This study looks to assist in the improvement of a website for both computer and mobile device usage, and propose suggestions for similar websites.
\end{abstract}

\section{RESEARCH OBJECTIVES \& PURPOSE}

The purpose of this study is to explore several ways to assist students in their statistical education through technology and mobile devices, such as websites, computer simulations, multimedia presentations, and more. Following are the research objectives:

- To evaluate the impact of mobile technology in advance statistical education.

- To analyze the responses of students for adoption of mobile technology in advance statistics education.

\section{METHODOLOGY}

Researcher has conducted this research through quantitative strategy by taking a close ended survey for acquiring primary data from the sample of 100 students which were selected through random sampling technique (Eggers, 2007).

\section{DISCUSSION}

In recent years there have been significant changes in the use of the Internet through mobile devices. Once students have successfully completed a statistics course, they should be able to think critically about material they encounter from media sources and come to logical, wellinformed decisions about the information (Rumsey, 2002). In recent years there have been significant changes in the use of the Internet through mobile devices. For example, dramatically increased the number of people using mobile devices to access social networks, and also increased use of smart phones in Asia (Moore, 1997, 123-137).

\section{IMPLICATIONS FOR THEORY \& PRACTICE}

The results indicate that students' who have a higher SATS scores at the beginning of the semester have more statistical literacy at the end of the class and gain more statistical literacy throughout the course.

Students who have higher attitudes towards statistics at the end of the class gained more statistical literacy throughout the course and had more literacy at the end of the course.

\section{CONCLUSION}

There is a significant positive impact of adoption of mobile technology on the students grades in advance statistical education. Students are inclined to adopt the mobile technology for advance statistics education.

\section{REFERENCES}

Eggers, W. D. (2007). Government 2.0: Using technology to improve education, cut red tape, reduce gridlock, and enhance democracy. Rowman \& Littlefield.

Moore, D. S. (1997). New pedagogy and new content: The case of statistics. International Statistical Review, 65,123-165.

Rumsey, D. J. (2002). Statistical literacy as a goal for introductory statistics courses. Journal of Statistics Education [Online], 10(3). 